\title{
STRUCTURE OF AQUEOUS SOLUTIONS \\ OF 1,2-, 1,3- AND 1,4-BUTANEDIOL INVESTIGATED BY POSITRON ANNIHILATION AND ULTRASONIC METHODS
}

\author{
K. Jerie ${ }^{a}$, A. Baranowski ${ }^{a}, \mathrm{~J}$ GLiński $^{b}, \mathrm{~K}$. ORzechowski $^{b}$ \\ AND J. PRZYBYLSKI ${ }^{b}$ \\ ${ }^{a}$ Institute of Experimental Physics, Wrocław University \\ Pl. M. Borna 9, 50-205 Wrocław, Poland \\ ${ }^{b}$ Faculty of Chemistry, Wrocław University \\ F. Joliot Curie 14, 50-383 Wrocław, Poland
}

\begin{abstract}
The structure of aqueous solutions of 1,2-, 1,3- and 1,4-butanediol was investigated using adiabatic compressibility measurements and positron annihilation methods. In the case of 1,2-butanediol the experimental results are very similar to those obtained earlier for systems where hydrophobic hydration dominates. In other cases there are evidences for increased rigidity of the water network, which arises from formation of hydrogen bonds between diols and water. Usefulness of both the methods applied in investigating the structure of liquid solutions was proved.
\end{abstract}

PACS numbers: 61.25.Em, 78.70.Bj

\section{Introduction}

Five decades ago, Frank and Evans [1] concluded that the large negative entropies of dissolution of apolar solutes in water can be explained by the formation of "microscopic icebergs" around the solute molecules. This concept was extended by Frank and Wen [2] to explain the singular heat capacity behaviour of tetraalkylammonium salts in water (short-lived clusters of water molecules are in equilibrium, and exchange rapidly with monomers). This idea was supported by the occurrence of clathrate hydrates for many apolar solutes and organic electrolytes [3].

In aqueous solutions, the long-lived component of the positron annihilation spectrum exhibits characteristic features around the solution composition corresponding to that of hydrates, if only the solute is hydrophobic or contains a hydrophobic moiety, as it was shown by us recently. On the other hand, the stoichiometry of the clathrate-like hydrates formed in the solution can be easily found 
from the interception point of compressibility isotherms, as it was done in series of aqueous solutions of short-chained alcohols [4] or of tetramethylurea [5].

Diols can build into the hydrogen-bonded water network. Moreover, the 1,2-diols are supposed to form crystalline-like hydrates similar structurally to the clathrates known for many nonelectrolytes, with stoichiometries close to $X \cdot 17 \mathrm{H}_{2} \mathrm{O}$ [6] (for details on clathrate hydrate stoichiometries see the review of Byk et al. [7]).

An additional impulse to investigate aqueous diols were recent publications on surface properties of 1,2-pentanediol [8] and 1,5-pentanediol [9] in water. The former behaves like typical surface-active component, while the latter causes very untypical concentration, as well as temperature dependences of surface tension.

In this paper aqueous solutions of 1,2-butanediol, $\mathrm{HOCH}_{2}-\mathrm{CH}(\mathrm{OH})-\mathrm{CH}_{2}$ $-\mathrm{CH}_{3}$, 1,3-butanediol, $\mathrm{HOCH}_{2}-\mathrm{CH}_{2}-\mathrm{CH}(\mathrm{OH})-\mathrm{CH}_{3}$, and 1,4-butanediol, $\mathrm{HOCH}_{2}-\mathrm{CH}_{2}-\mathrm{CH}_{2}-\mathrm{CH}_{2} \mathrm{OH}$, were investigated using independently the sound velocity and positron annihilation methods. The main goal was to study whether the solutes under tests form inclusion-type hydrates in liquid aqueous mixtures, and how formation of these hydrates reflects in the annihilation spectrum.

\section{Experimental}

\subsection{Chemicals}

1,2-butanediol (Fluka AG, pure), 1,3-butanediol (Riedel de Haën, >99\%) and 1,4-butanediol (Riedel de Haën, pure for analysis) were used without further processing. Water was doubly distilled. Solutions were prepared by weighting.

\subsection{Positron annihilation measurements}

The annihilation measurements were carried out at room temperature (approximately $20^{\circ} \mathrm{C}$ ) with a standard measuring device based on the "fast-slow" coincidence technique as described elsewhere [10]. Solutions were refluxed with nitrogen before the measurements to remove oxygen dissolved in the samples. The obtained spectra were resolved using POSITRONFIT program.

\subsection{Sound velocity measurements}

The ultrasonic velocity was measured at temperatures between 15 and $35^{\circ} \mathrm{C}$ with 2 or $3^{\circ} \mathrm{C}$ intervals (stabilized and measured with an accuracy of $\pm 0.01^{\circ} \mathrm{C}$ ) with an accuracy of $\pm 0.1 \mathrm{~m} / \mathrm{s}$ using a "sing-around" equipment (apparatus Ecolab MPFU, Kraków, Poland). The principles of the apparatus and measurement techniques applied in this study are given in [11].

\subsection{Density measurements}

Densities were measured at the same temperatures as sound velocity using a vibrating tube densitometer type Ecolab MG-2 (Kraków, Poland). The accuracies of the densities are better than $\pm 0.05 \mathrm{~kg} / \mathrm{m}^{3}$. 


\section{Results and discussion}

\subsection{Acoustic measurements}

From the sound velocity $(c)$ and density $(d)$ data, using the Laplace formula $\beta=\left(c^{2} d\right)^{-1}$ the adiabatic compressibility coefficients $(\beta)$ of solutions were calculated. They are shown in Fig. 1.
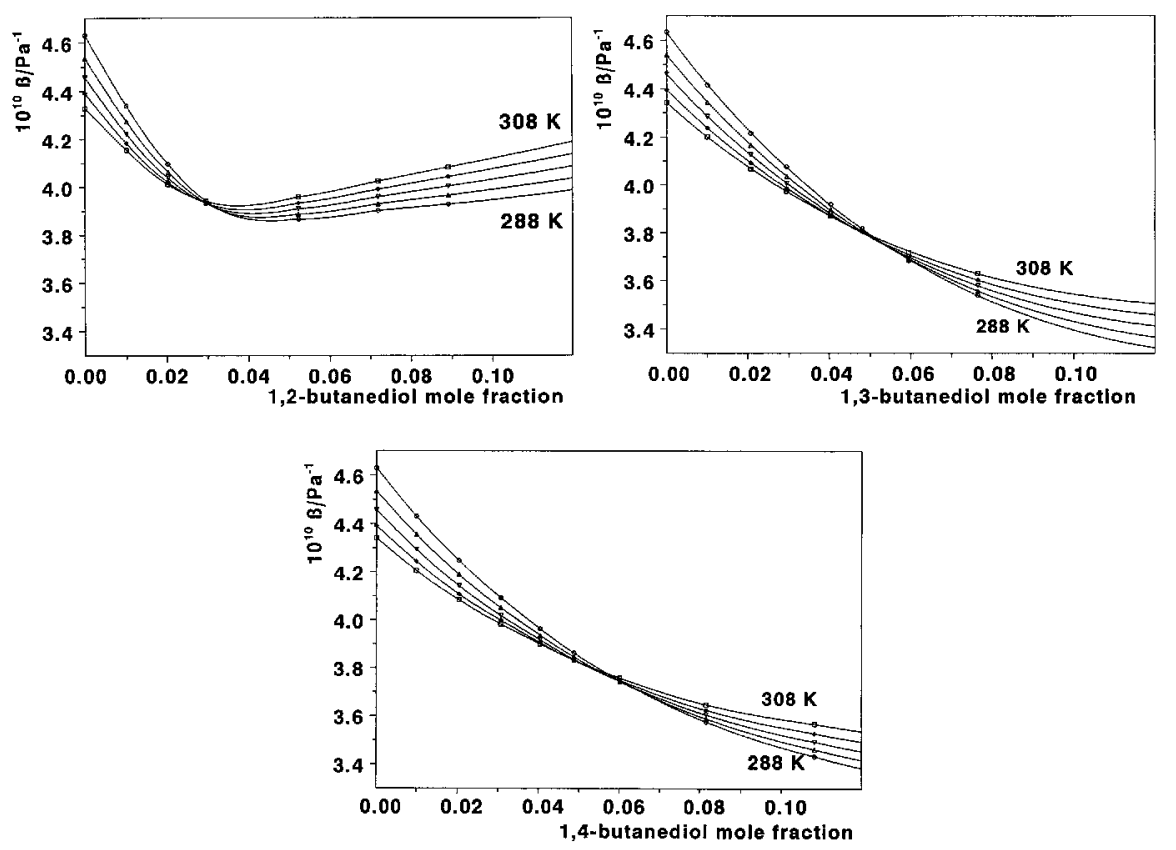

Fig. 1. Plots of adiabatic compressibility coefficients vs. mole fraction of 1,2-, 1,3- and 1,4-butanediol in water. $\bigcirc-288 \mathrm{~K}, \triangle-293 \mathrm{~K}, \nabla-298 \mathrm{~K}, \diamond-303 \mathrm{~K}, \square-308 \mathrm{~K}$, lines are drawn arbitrarily (spline function).

For 1,3- and 1,4-butanediol solutes, the concentrations corresponding to the intersections of compressibility isotherms decrease with temperature. For 1,2-butanediol the intersection is located at the solute mole fraction about 0.03 and is almost temperature independent.

According to Endo [12], concentration of the intersection of the compressibility isotherms corresponds to the stoichiometry of clathrate hydrates (if formed). While this is supposed in the case of water $+1,2$-butanediol system, the hypothetical hydrate should be about $X \cdot 32 \mathrm{H}_{2} \mathrm{O}$ - higher than those of the known clathrate hydrates. For 1,3- and 1,4-butanediols, concentrations corresponding to the intersection are not constant, suggesting dominating hydrophilic hydration. Note that compressibility reaches at the intersection values of $\beta \approx 3.95 \times 10^{-10} \mathrm{~m}^{2} / \mathrm{N}$, $3.80 \times 10^{-10} \mathrm{~m}^{2} / \mathrm{N}$ and $3.75 \times 10^{-10} \mathrm{~m}^{2} / \mathrm{N}$ for $1,2-, 1,3$ - and 1,4 -butanediol, respectively. The former is very close to, but the latter are considerably lower than 
that of solid clathrates, determined by von Stackelberg and Müller [13] (for the type II clathrate hydrates $\beta \approx 4 \times 10^{-10} \mathrm{~m}^{2} / \mathrm{N}$ ). Lower $\beta$ value at the intersection means that only partial or no hydrophobic hydration of the solutes occurs in this system (see for illustration the results for the system water + tetramethylammonium chloride [14]). Thus, the ultrasonic results give no evidence for formation of clathrate-like hydrates in liquid phase in the cases of 1,3- and 1,4-butanediol, but suggest their formation for 1,2-butanediol solute.

\subsection{Positron annihilation measurements}

The experimental lifetime spectra were resolved into three components, each characterized by its lifetime $\left(\tau_{1}, \tau_{2}\right.$, and $\left.\tau_{3}\right)$, and intensity $\left(I_{1}, I_{2}\right.$, and $\left.I_{3}\right)$. The number of components was chosen arbitrarily, only the long-lived one $\left(\tau_{3}\right.$ and $I_{3}$ ), attributed to ortho-positronium annihilation, is of interest for further discussion. The short-lived components can be attributed to many different annihilation mechanisms and their more detailed analysis seems impossible. The results of annihilation experiments (parameters of the long-lived component of the spectrum) are collected in Figs. 2 and 3. For comparison, our previous results obtained for water + ethanol mixtures [15] are included in these figures (dashed lines). The system water + ethanol was chosen as a typical hydrophobic one, where hydrate structures are undoubtely formed in liquid phase. Both the characteristic features are observed in the water $+1,2$-butanediol system: $\tau_{3}$ has a deflection of the plateau and $I_{3}$ has a maximum exactly at $X=0.03$. However, for 1,3- and 1,4-butanediol the long-lived component $\tau_{3}$ increases monotonically (no plateau occurs), although the $I_{3}$ parameter passes through maximum, for 1,4-butanediol even more distinct than for 1,2-butanediol or ethanol.

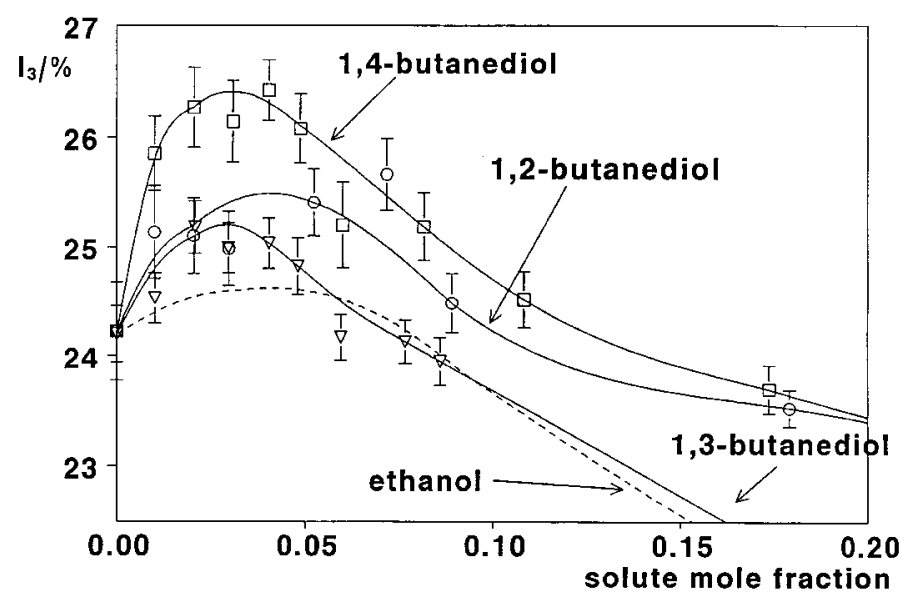

Fig. 2. Intensities of the long-lived component of annihilation spectra vs. butanediols concentration in water. Broken line: the results for aqueous solutions of ethanol [15].

The interpretation is substantially similar to that arising from acoustic measurements given above. In the region of low concentrations of 1,2-butanediol (below $X=0.1$ ) clathrate hydrates are formed in liquid state, with stoichiometry 


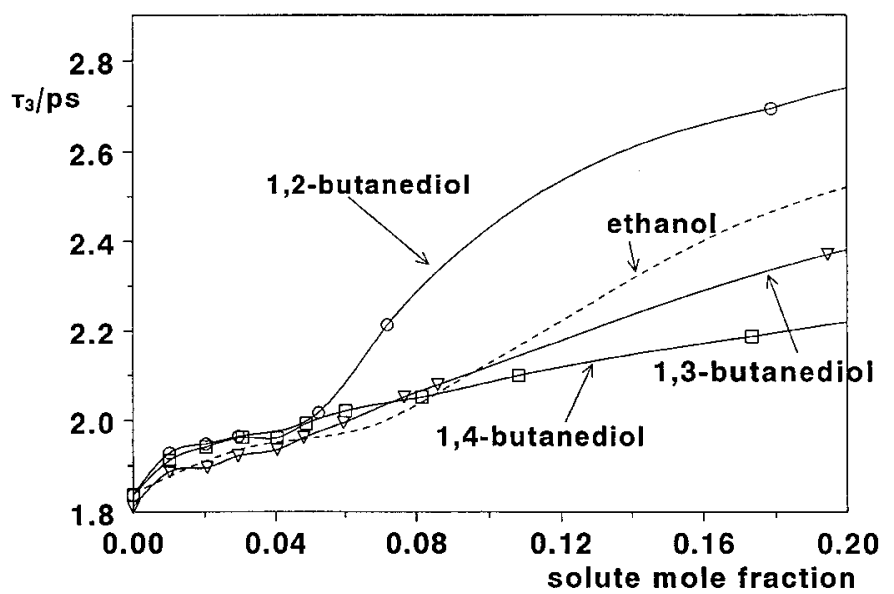

Fig. 3. Lifetimes of the long-lived component of annihilation spectra vs. butanediols concentration in water. Broken line: the results for aqueous solutions of ethanol [15].

about $X \cdot 32 \mathrm{H}_{2} \mathrm{O}$, much more water-rich than those known for solid inclusion compounds [7]. For water $+1,3$ - or 1,4-butanediol, formation of such hydrates seems rather doubtful.

The question remains, why the $I_{3}$ parameter passes through maximum for the latter systems, too. In our recent papers cited above the appearance of such maxima was interpreted in terms of increased stability of voids in water network. In the light of the present results, however, this concept seems to be incorrect. While in water $+1,4$-butanediol the maximum is even more distinct than for the systems which undoubtely form crystalline-like hydrates (aqueous solutions of ethanol and 1,4-butanediol), the only interpretation is that such maxima reflect increased local electron density and/or locally increased rigidity of water network. This explains the observed phenomenon: 1,4-butanediol incorporates into the original water structure and its local environment should be more rigid and denser than the structure of pure water. In the case of 1,2-butanediol, close to its polar (containing the $\mathrm{OH}$ groups) end, density and rigidity increases, too, but this effect is partly diminished by formation of cavities of open-work network. On the other hand, the $\tau_{3}$ parameter should detect both the changes in rigidity of the water framework and the changing number and size of cages. Thus, the mechanism of increasing rigidity could be different (ethanol and 1,2-butanediol: formation of clathrate-like hydrates, 1,3- and 1,4-butanediol: three-dimensional $\mathrm{H}$-bonds between water and the solute).

\section{Conclusions}

The ultrasonic results (concentration dependencies of compressibility) suggest dominating hydrophobic character of hydration of 1,2-butanediol dissolved in water and formation of clathrate-like hydrates in this system. The concentration dependencies of positron annihilation parameters (lifetimes and intensities of the long-lived component of annihilation spectrum) are similar to those found in the 
known clathrate-forming polar organic solutes, suggesting increasing rigidity and increasing number of voids in the structure when 1,2-butanediol is added to water (the cage-building). Other butanediols interact with water framework rather hydrophilically than hydrophobically: in the cases of 1,3- and 1,4-butanediol, increased rigidity of water framework gives a maximum of the $I_{3}$, but no deflection of $\tau_{3}$ parameter is observed.

\section{Acknowledgments}

This work was partially supported by the Committee for Scientific Research, grant No. 2016/GW/IFD/2000.

\section{References}

[1] H.S. Frank, M.W. Evans, J. Chem. Phys. 13, 478 (1945).

[2] H.S. Frank, W.Y. Wen, Discuss. Faraday Soc. 24, 133 (1957).

[3] D.W. Davidson, in: Water. A Comprehensive Treatise, Ed. F. Franks, Vol. 2, Plenum Press, New York 1973, Ch. 3, p. 115.

[4] K. Jerie, A. Baranowski, B. Rozenfeld, J. Gliński, S. Ernst, Phys. Scr. 35, 729 (1987) and papers cited therein.

[5] Gy. Jákli, A. Baranowski, K. Jerie, J. Gliński, K. Orzechowski, Bull. Pol. Acad. Sci.: Chem. 42, 71 (1994).

[6] See for example S. Ernst, J. Gliński, Mater. Sci. III/3, 69 (1977) (the system water + dioxane).

[7] S.Sh. Byk, Yu.F. Makogon, V.I. Fomina, in: Gazovye Gidraty, Ed. G.N. Gosteeva, Izd. Khimia, Moskva 1980, p. 12 and further (in Russian). For the collection of possible stoichiometries of clathrate hydrates see also Yu.A. Dyadin, Supramolec. Chem. 6, 59 (1995).

[8] J. Gliński, G. Chavepeyer, J.-K. Platten, J. Chem. Phys. 111, 3233 (1999).

[9] J. Gliński, G. Chavepeyer, J.-K. Platten, Coll. Surf. A 162, 233 (1999).

[10] K. Jerie, A. Baranowski, B. Rozenfeld, S. Ernst, J. Gliński, Acta Phys. Pol. A 64, 77 (1983).

[11] S. Ernst, J. Gliński, B. Jeżowska-Trzebiatowska, Acta Phys. Pol. A 64, 501 (1979).

[12] H. Endo, Bull. Chem. Soc. Jpn. 16, 1586 (1973).

[13] M. von Stackelberg, H. Müller, Z. Elektrochem. 58, 25 (1954).

[14] Gy. Jákli, K. Jerie, A. Baranowski, J. Gliński, Acta Phys. Pol. A 93, 649 (1998).

[15] K. Jerie, A. Baranowski, S. Ernst, J. Gliński, Acta Phys. Pol. A 69, 81 (1986). 